See Article page e203.

\section{Commentary: Wanted: A reliable, unhindered, and more robust cardiac surgery pipeline}

\author{
Fatima G. Wilder, MD, MS, and \\ Jennifer S. Lawton, MD
}

Despite the well-known and previously discussed need for an increase in the female cardiothoracic surgeon presence in the field, the reality of female representation does not align. ${ }^{1}$ This is a chronic problem that is not limited by geography and has been reported in several countries. ${ }^{2,3}$ Inadequate female representation in the field of cardiothoracic surgery is an extremely important topic in that a paucity of female surgeons in the workforce as well as in leadership positions ultimately limits the diversity of experiences, perspectives, and skills that women can bring to the field. ${ }^{1,4}$ In addition, it leads to a limited number of potential mentors and role models for women who aspire to a career in cardiothoracic surgery.

Similar to others, Servito and colleagues ${ }^{5}$ highlight that the issue of female faculty representation not being on par with that of male faculty is not unique to cardiac surgery, but in fact it exists across multiple subspecialties in medicine. ${ }^{6}$ They importantly demonstrate that interest is increasing, with an increase in applicants for training and an even distribution between male and female trainees accepted to medical school. However, they note that the number of female faculty has remained relatively stagnant. They describe an increase in cardiac surgery staff from 5\% to $10 \%$ over the course of 23 years in Canada. In 2021, they report only 1 in 13 program directors and 2 in 33 division chiefs are women in Canada. This suggests that the real problem is in retention and advancement in the field, known as the "leaky pipeline."

We only wish that additional strategies or suggestions to solve this problem could have been included in this

\footnotetext{
From the Division of Cardiac Surgery, Department of Surgery, Johns Hopkins University, Baltimore, Md.

Disclosures: The authors reported no conflicts of interest.

The Journal policy requires editors and reviewers to disclose conflicts of interest and to decline handling or reviewing manuscripts for which they may have a conflict of interest. The editors and reviewers of this article have no conflicts of interest.

Received for publication June 23, 2021; revisions received June 23, 2021; accepted for publication June 24, 2021; available ahead of print June 29, 2021.

Address for reprints: Jennifer S. Lawton, MD, Division of Cardiac Surgery, Department of Surgery, Johns Hopkins School of Medicine, 1800 Orleans St, Zayed 7107, Baltimore, MD 21287 (E-mail: jlawton4@jhmi.edu).

J Thorac Cardiovasc Surg 2022;163:e209-10

$0022-5223 / \$ 36.00$

Copyright (C) 2021 by The American Association for Thoracic Surgery

https://doi.org/10.1016/j.jtcvs.2021.06.048
}

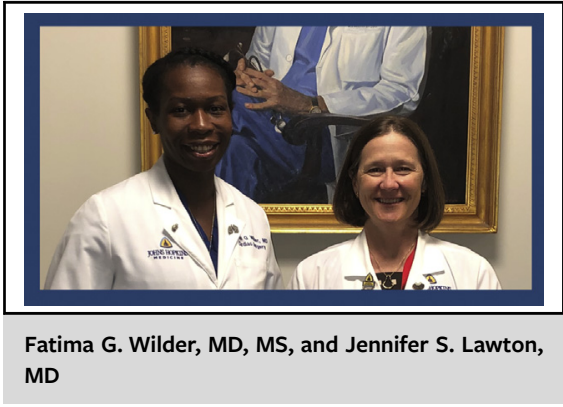

\section{CENTRAL MESSAGE \\ Progress has been made in the recruitment of women to cardiac surgery in Canada over the last 23 years; however, important deficits remain in female faculty and leadership positions.}

manuscript. A paper such as this could serve as a guide for aspiring female cardiothoracic surgeons to identify tools to use to increase exposure to the field, address barriers and potential biases in advancement, and to train leaders and sustain interest and success. Further exploration of this important topic is warranted to highlight useful tools and to serve as a strategic guidebook for female cardiothoracic surgeons.

The information provided by Servito and colleagues ${ }^{5}$ may be disseminated to hospital and academic leadership. It serves as a call to action with regards to establishing steps that institutions can take to recruit, retain, and develop female trainees and faculty. We must support a reliable, unhindered, and more robust cardiac surgery pipeline for women as well as invest our attention in recruitment, mentorship, and sponsorship. ${ }^{7}$ Significant focus should be placed on career building, leadership training, research support, and overall retention of practicing female cardiothoracic surgeons, particularly because a shortage of cardiothoracic surgeons is predicted for the future. ${ }^{8}$ If these areas are prioritized, the results can only serve to benefit patients as well as institutions. ${ }^{9}$

\section{References}

1. Donington JS, Litle VR, Sesti J, Colson YL. The WTS report on the current status of women in cardiothoracic surgery. Ann Thorac Surg. 2012;94:452-9.

2. Fertouk M, Bekerman Z, Kremer R, Adler Z, Bolotin G. Women pioneers: first female cardiothoracic surgeons in the USA and in Israel. Harefuah. 2014;153:487-8. 496 [in Hebrew].

3. Vosloo SM. Realities and challenges for female cardiothoracic surgeons: an African perspective. J Thorac Dis. 2021;13:448-55. 
4. Ortmeyer KA, Raman V, Tiko-Okoye C, Espinosa J, Cooke DT, Erkmen CP. Women and minorities underrepresented in academic cardiothoracic surgery: it's time for next steps. Ann Thorac Surg. November 5, 2020 [Epub ahead of print].

5. Servito M, Ouzounian M, Chung J, Yanagawa B. Trends in female cardiac surgery trainees and staff in Canada: 1998 to 2020. J Thorac Cardiovasc Surg. 2022;163: e203-6.

6. Jagsi R, Means O, Lautenberger D, Jones RD, Griffith KA, Flotte TR, et al. Women's representation among members and leaders of national medical specialty societies. Acad Med. 2020;95:1043-9.
7. Pories SE, Turner PL, Greenberg CC, Babu MA, Parangi S. Leadership in American surgery: women are rising to the top. Ann Surg. 2019;269: 199-205.

8. Moffatt-Bruce S, Crestanello J, Way DP, Williams TE Jr. Providing cardiothoracic services in 2035: signs of trouble ahead. J Thorac Cardiovasc Surg. 2018;155: 824-9.

9. Wallis CJ, Ravi B, Coburn N, Nam RK, Detsky AS, Satkunasivam R. Comparison of postoperative outcomes among patients treated by male and female surgeons: a population based matched cohort study. BMJ. 2017;359:j4366. 